\title{
Analysis of Antimicrobial Activities of Photoactivated Cow Urine against Common Human Pathogens
}

\author{
Monica A. Godad*, Siddhi S. Suryavanshi, Somesh S. Shintre, Kiran K. Abitkar \\ *Department of Agrochemicals and Pest Management, Shivaji University, Kolhapur -416004
}

\begin{abstract}
A concurrent and promising effects has been achieved by using cow urine as a efficient antibacterial activity against gram-negative and gram-positive human pathogen. The present study aims to evaluate anti-microbial activity photo activated cow urine against pathogenic bacterial strains. It is estimated by agar well diffusion method.It is evident from the data presented that the zone of inhibition of photo activated Gir cow urine and Khillari cow urine against bacteria Escherichi coli and staphulococcus aureus is significant.The present investigation clearly demonstrate that the average width of inhibition zone at 50 micrilitre dose was $1.6 \mathrm{~cm}$. Therefore this pathogen can be well managed by using cow urine.
\end{abstract}

Keywords:- Photo activated Gir cow urine and khillari cow urine, E.coli, S. aureus, well diffusion method.

\section{INTRODUCTION}

Cow urine is employed for purposes of therapy in traditional Indian medicine and is named Gomutra. In susruta (45/221) and in charak (sloka-100) several medicinal properties of cow urine have been mentioned such as weight loss, anaemia, enema, jaundice, skin diseases including vitiligo. Cow urine contains $95 \%$ water, $2.5 \%$ urea, minerals, 24 sorts of salts, hormones and $2.5 \%$ enzymes it also contains iron, calcium, phosphorus, carbonic acid, manganese, sulphur, urea, amino acids, cytokine. Cow urine is an efficient antibacterial against gram-negative and gram-positive bacteria. Now a days certain synthetic antimicrobial agents are used to treat the infectious diseases caused by microorganisms. But as a synthetic antibiotics shows ill side effects on human most of the time natural antimicrobial agents are preferred. Cow urine is an immune-enhancer also.

\section{MATERIALS AND METHODS}

Apparatus: Petri dishes, conical flask, test tubes, test-tube stand, spirit lamp, cotton plugs, rubber bands papers, gas burner, portable autoclave, matchbox, micropipette, laminar air flow.

Chemicals: Distilled water, nutrient agar, 100\% alcohol, agar agar powder, saline
$>$ Bacteria used:

- Escherichia coli

- Staphylococcus aureus

Photo activated urine for 72 hours of Gir and Khillari

\section{METHODOLOGY}

\section{A. Collection of cow urine:}

Two healthy, disease free cows of Bos indicus (Gir and Khillari indigenous breed) are selected for urine collection. For collection adult dewellers having age of more than 4 years were selected. The urine from Gir and Khillari breed collected from Goshala, Kanerimath, Kolhapur Maharashtra, India. Where, the all breed were maintained in a well-ventilated shed with the provision of individual feeding and watering. The urine was pooled, separately and transported to laboratory in air tight sterile container.

\section{B. Preparation of photo activated cow urine:}

The sterile glass bottles filled with cow urine was kept in sunlight for 72 hours for the preparation of the photo activate cow urine.

\section{Bacterial Culture:}

Culture of two bacterial pathogen strain of each of Escerichia coli, Staphylococcus aureus were maintained in the laboratory on Nutrient Agar (NA, Himedia) stored at $37^{\circ} \mathrm{c}$ for before used in experiments obtained from Department.

\section{Autoclaving/Moist Heat Sterilisation and Preparation of Media:}

All the apparatus required i.e. petri plate, conical flask was cleaned using water. 5.6gm Nutrient Agar was weighed.200ml of distilled water was taken in conical flask and then Nutrient Agar was added.It was shaked well and the mouth of conical flask was plugged use in cotton plug.The petri plates, conical flask, forceps were wrapped using papers and rubber bands. The wrapped requirements were put in portable autoclave.The autoclave was placed on gas and the pressure was allowed to $15 \mathrm{psi}$ and the autoclave was left on gas for $45 \mathrm{~min}$, at the temperature $121^{\circ} \mathrm{c}$ released.After $45 \mathrm{~min}$, the autoclave was allowed to cool down and the pressure was released. 


\section{E. Creation of Aseptic Area:}

Aseptic area was created by the laminar air flow. Laminar air flow floor was wiped with $70 \%$ alcohol.Switched on UV light for $15 \mathrm{~min}$ and after $15 \mathrm{~min}$ UV light switched off and tube light and HEPA filter is started.

All the requirement were removed from the autoclave and placed in aseptic area.

\section{F. Plating and Inoculation of Microorganism in the Medium:}

The autoclaved media in the conical flask was allowed to cool down to $55^{\circ} \mathrm{C}$. Then approximately $20 \mathrm{ml}$ media was poured in petri plates and plates allow cool down.Suspension of the Escherichia coli and Staphylococcus aureus culture was prepared in sterile saline.With the help of micropipette $10 \mu$ l suspension was added into the petri plate with solidify media.The added suspension was spread on the petri plate with the help of glass spreader.For each of the strain of bacteria 8 plates was prepared.

\section{G. Antibacterial Activity of Cow Urine:}

Now the further procedure were followed for well formation method.

\section{* Well method:-}

The 6 sterile petri plates with nutrient media and inoculated bacterial suspension was taken for analysis of antibacterial activity of cow urine by well method.Firstly, the base of the petri dishes was labelled with the name of cow urine and bacterial culture. With the help of sterilized glass borer, a well was prepared at the centre of the media

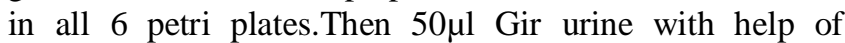
micropipette was added in the prepared well.Similarly, same procedure was repeated for Khillari and Gir urine 3 times for each species.

\section{H. Microbial Analysis of Cow Urine:}

The 2 sterile petri plates were taken.50ml Nutrient media was prepared and autoclaved.Autoclaved media were poured in petri plates and allowed to solidify (cool down) Photo activated cow urine was inoculated onto the media with the help of micropipette and spreaded with the help of glass spreader. Care was taken to avoid contamination.Plates were incubated at $37^{\circ} \mathrm{C}$ for 24 hours $\&$ observed for presence of microorganism.

\section{* OBSERVATIONS:-}

The setup of well formation method were left undisturbed at room temperature in aseptic conditions. After 24 hour, the following observations were noted.

\section{Well Method:}

The petri plates having well and inoculated with photo activated cow urine was observed. After 24 hours the observations are as follows,

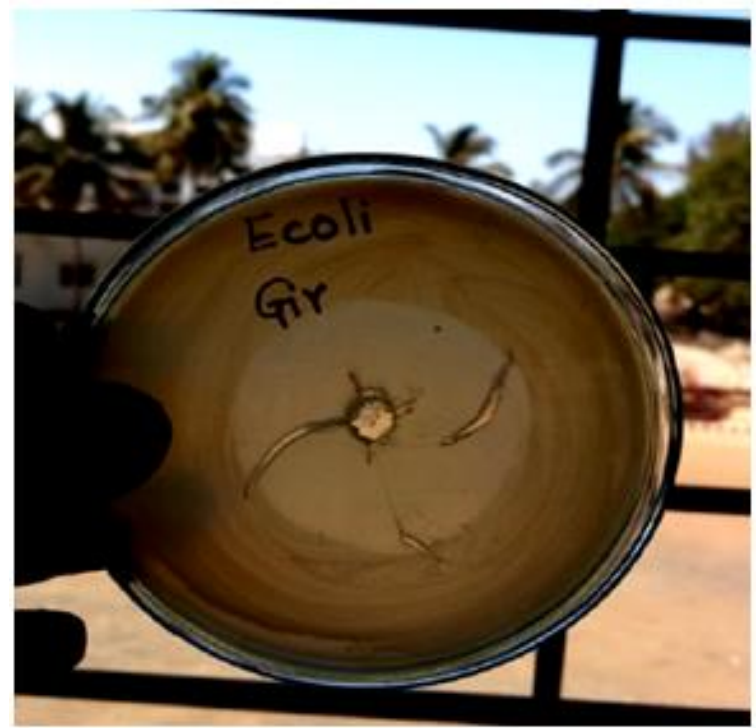

Fig 1 (a): Zone of inhibition for Gir

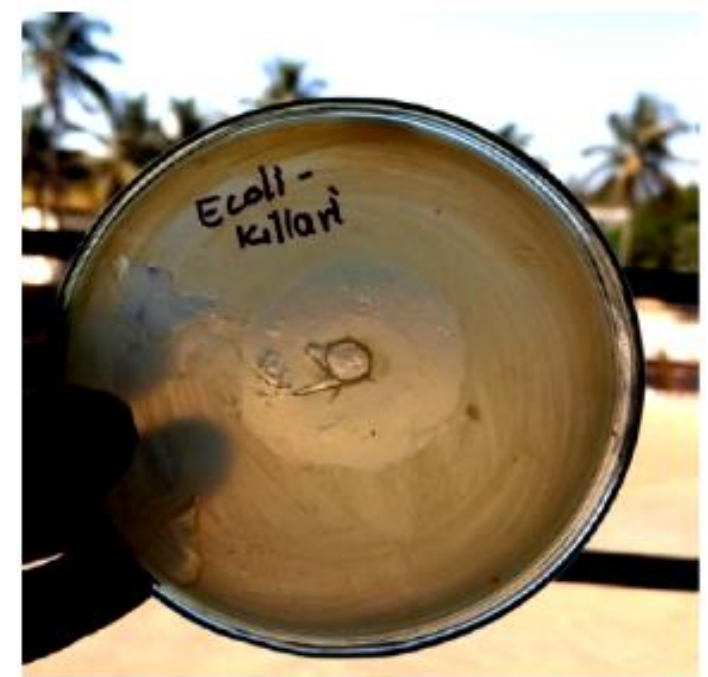

Fig 1 (b) Zone of inhibition formed by Khillari

Fig 1:- Zone of inhibition formed around the well filled with cow urine in E. coli suspension containing petri plates by well formation method

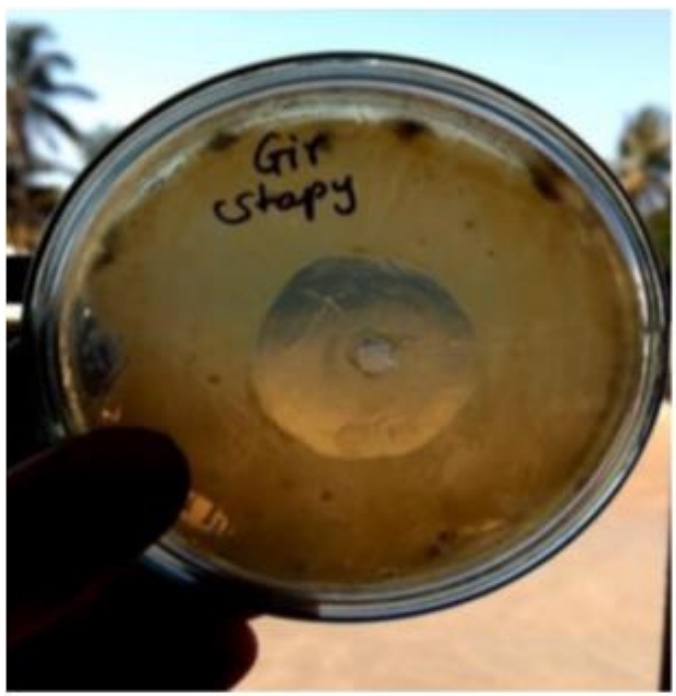

Fig 2 (a): Zone of inhibition for Gir 


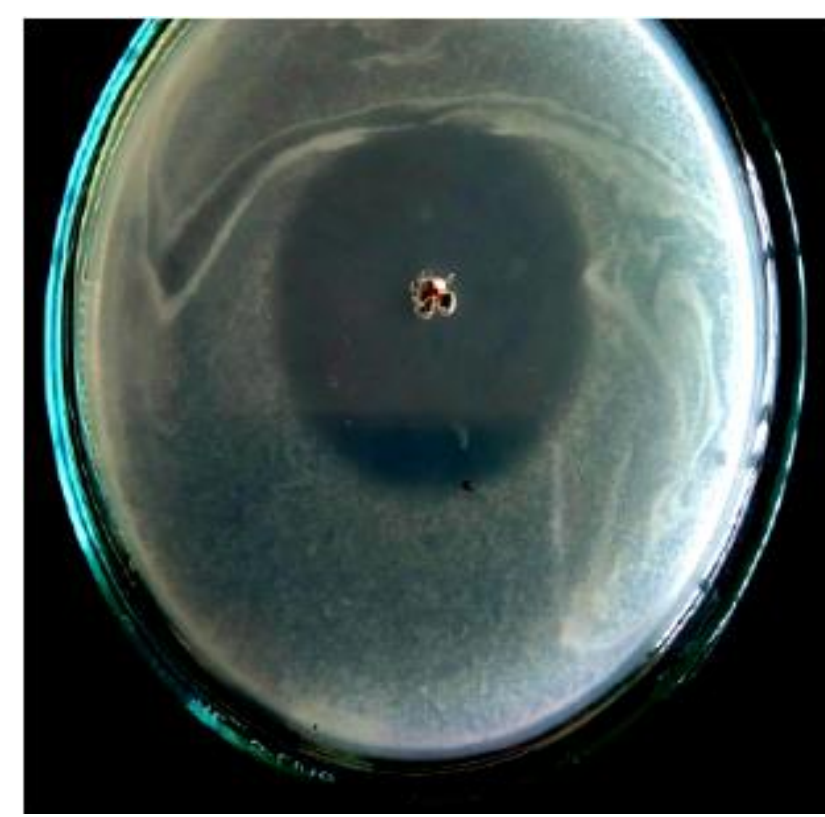

Fig 2 (b) Zone of inhibition for Khillari

Fig 2:- Zone of inhibition formed around the well filled with cow urine in staphylococcus aureus.

- The clear zones around each well are the zone of inhibition that indicates the extent of Escherichia coli inability to survive in presence of photo activated Gir \& Khillari cow urine. ( Fig 1)

- The clear zones around each well are the zone of inhibition that indicates the extent of Staphylococcous aureus inability to survive in presence of photo activated Gir and Khillari cow urine. ( Fig 2)

- In the Fig 1 diameter of zone of inhibition formed around the well is of photo activated.Gir cow urine is $1.5 \mathrm{~cm}$ and photo activated khillari cow urine is 1.6 with E.coli was observed.

- In the Fig 2 diameter of zone of inhibition fomed around the well is of photo activated Gir cow urine is $1.8 \mathrm{~cm}$ and photo activated khillari cow urine is 1.6 with Staphylococcus aureus was observed.

\section{$>$ Microbial Analysis of Photo activated Cow Urine:}

The nutrient agar plates inoculated with the photo activated cow urine incubated at $37^{\circ} \mathrm{C}$ was observed after 24 hours. Different types of microbial colonies were observed but which are very few (Fig 3 and Fig 4)

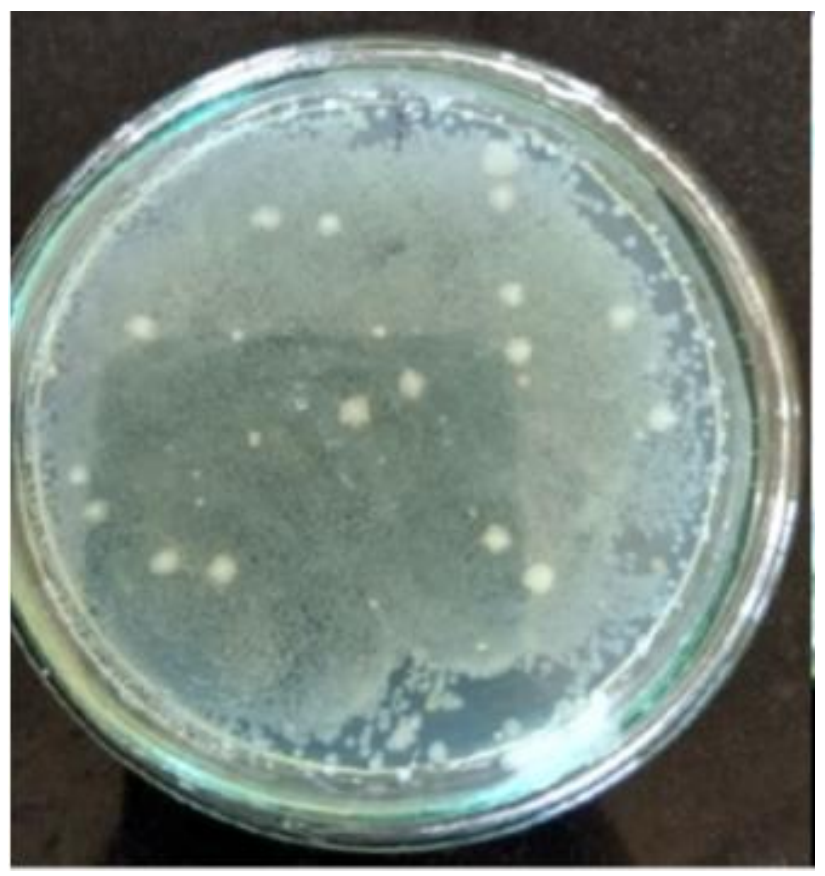

Fig 3:- Microbial analysis of Photoactivated Gir cow urine

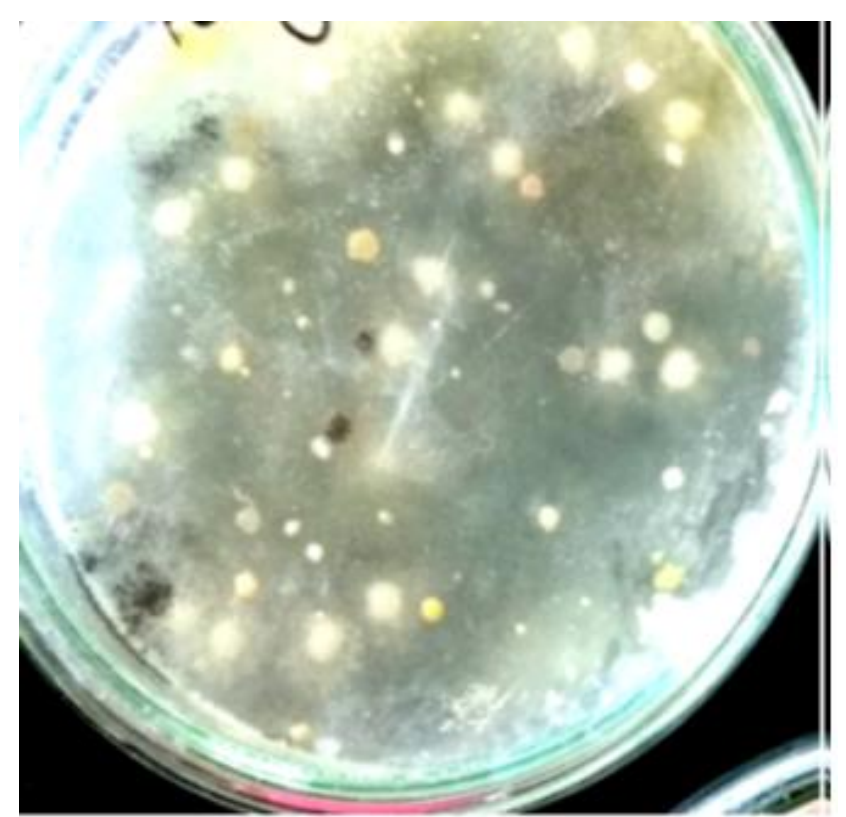

Fig 4:- Microbial analysis of Photoactivated Khilari cow urine

- Microbial Analysis of Photo activated Gir Cow Urine:

\begin{tabular}{|c|c|c|c|c|c|c|c|}
\hline Sr. No & Shape & Elevation & Margin & Size & Consistency & Colour & Opacity \\
\hline 1. & Round & Convex & Smooth & $2 \mathrm{~mm}$ & Moist & Milky white & Opaque \\
\hline
\end{tabular}

- Microbial Analysis of Photo activated Khillari Cow Urine:

\begin{tabular}{|c|c|c|c|c|c|c|c|}
\hline Sr. No & Shape & Elevation & Margin & Size & Consistency & Colour & Opacity \\
\hline 1. & Round & Convex & Smooth & $2 \mathrm{~mm}$ & Moist & Milky white & Opaque \\
\hline 2. & Irregular & Convex & Smooth & $1.6 \mathrm{~mm}$ & Moist & Yellow & Opaque \\
\hline
\end{tabular}




\section{RESULT AND DISCUSSIONS}

Antimicrobial activity of photo activated cow urine against pathogenic bacterial strains estimated by agar well diffusion method showed different diameters of zone of inhibition against various human pathogenic bacterial strains. Thus, photo activated cow urine had significant antibacterial activity. Antimicrobial activity was seen against bacterial pathogens Stphylococcus aureus and Escherichia coli. The average width of inhibition zone at this dose was $1.6 \mathrm{~cm}$. The highest antimicrobial activity, represented by a $1.8 \mathrm{~cm}$ inhibition zone was evident for Khillari cow urine and the lowest activity $(0.2 \mathrm{~cm}$ zone) cow urine against Staphylococcus aureus.

Well Method:

\begin{tabular}{|c|c|c|}
\hline \multirow{2}{*}{ Name of the bacteria } & \multicolumn{2}{|c|}{$\begin{array}{c}\text { Diameter of zone of } \\
\text { inhibition in cm }\end{array}$} \\
\cline { 2 - 3 } & Gir & Khillari \\
\hline Escherichia coli & 1.5 & 1.6 \\
\hline \multirow{2}{*}{ Staphylococcus aureus } & 1.8 & 1.6 \\
\hline
\end{tabular}

Table 3

Microbial analysis of photo activated cow urine:

The biochemical analysis of strains observed in this microbial analysis was not done.

\section{REFERENCES}

[1]. African Journal of Biotechnology Vol. 9 (4), pp. 518522, 25 January, 2010 Available online at http://www.academicjournals.org/AJB ISSN 16845315 (C) 2010 Academic Journals

[2]. Bhadauria H. Cow urine- A magical therapy. Int J Cow Sci. 2002;1:32-6.

[3]. Chauhan RS, Garg N. Banglore, Karnataka: Indian Science Congress; 2003. Cow Therapy as an Alternative to Antibiotic.

[4]. Chauhan RS, Singh BP, Singhal LK. Immunomodulation with Kamdhenu ark in mice. J Immunol Immunopathol. 2001;3:74-7

[5]. .Cow urine (Wikipedia )

[6]. Kingston W (June 2008). "Irish contributions to the origins of antibiotics". IrishJournal of Medical Science.177 (2): 87-92. doi:10.1007/s11845-0080139- x. PMID 18347757.

[7]. M. Wainwright (1989). "Moulds in ancient and more recent medicine". Mycologist. 3 (1): 21-23. doi:10.1016/S0269-915X(89)80010-2.

[8]. Microorganisms (Wikipedia)

[9]. Murray C.K. 2008. Infectious disease complications of combatrelated injuries. Crit. Care Med. 36: S358364 .
[10]. Ojewole J., Olusi SO. 1976. Effects of cow's urine concoction on plasma glucose concentration in fasted rats. J.Trop. Med. Hyg. 79: 241-245

[11]. Randhawa GK, Kullar JS, Rajkumar Bioenhancers from mother nature and their applicability in modern medicine. Int J Appl Basic Med Res. 2011;1:5-10. [PMC free article] [PubMed]

[12]. Wolfgang Saxon (9 June 1999). "Anne Miller, 90, First Patient Who Was Saved by Penicillin". New York Times. Retrieved 29 August 2014.

[13]. Yadav H., Yadav M., Jain S., Bhardwaj A., Singh V., Parkash O., Marotta F. 2008. Antimicrobial property of an herbal preparation containing Dalbergia sissoo and Datura stramonium with cow urine against pathogenic bacteria. Int. J. Immunopathol. Pharmacol. 21: $1013-1020$ 